\title{
Personality-cognition associations across the adult life span and potential moderators: Results from two cohorts
}

\author{
Sharon S. Simon ${ }^{1}$ (D) | Seonjoo Lee ${ }^{2}$ | Yaakov Stern ${ }^{1}$
}

${ }^{1}$ Cognitive Neuroscience Division, Department of Neurology, Columbia University, New York, NY, USA

${ }^{2}$ Department of Biostatistics, Mailman School of Public Health, Columbia

University, New York, NY, USA

\section{Correspondence}

Yaakov Stern, Taub Institute, $630 \mathrm{~W}$ 168th Street, New York, NY 10032, USA.

Email: ys11@columbia.edu

Funding information

National Institute of Aging, Grant/ Award Number: R01AG026158 and RF1AG038465

\begin{abstract}
Objective: Personality and cognitive abilities have been previously linked. However, there are inconsistencies regarding whether this relationship varies as a function of age, and a lack of evidence on whether gender contributes to this relation, particularly across the adulthood. Therefore, this study investigated the association between personality and cognition across the adult life span, accounting for age and gender.

Methods: We examined the association between personality and cognition in two large samples (Sample 1: $N=422$; Sample 2: $N=549$ ) including young, middleaged and older adults. Participants completed personality scales and several cognitive measures related to reasoning, language, memory and speed of processing. Structural equation modeling was applied in order to investigate associations between personality and cognition, and moderation of age and gender within this relationship. We also conducted a mini-meta-analysis procedure in order to examine personality-cognition associations, combining results from the two samples.
\end{abstract}

Results: Openness was the main trait associated with cognitive performance; however, Extraversion, Conscientiousness, and Neuroticism were also independently associated with cognition. Age and gender did not consistently moderate personalitycognition in each sample, but the mini-metanalysis showed that gender moderated Conscientiousness-cognition associations.

Conclusions: We provided robust evidence of personality-cognition associations across the adult life span, which was not consistently moderated by age, but in part by gender.

\section{K E Y W O R D S}

aging, cognition, gender, life span, personality

\section{1 | INTRODUCTION}

There has been a growing interest in the extent to which personality characteristics are related to cognitive functioning and cognitive aging. The examination of personality implications for health and cognition has a long history in the behavioral and biomedical sciences (Ackerman \& Heggestad, 1997; Bogg \& Roberts, 2013; DeYoung, Peterson, \& Higgins, 2005; Moutafi, Furnham, \& Crump, 2003; Smith \& Spiro, 2002; Sutin, Stephan, \& Terracciano,
2018). Nevertheless, in the last decade there has been an increasing interest in investigating how personality is associated with cognitive performance across the adult life span (including older population), and possible moderators of this association (Curtis, Windsur, \& Soubelet, 2015; Graham \& Lachman, 2012, 2014; Rammstedt, Danner, \& Martin, 2016; Soubelet \& Salthouse, 2011). Personality traits describe individual differences in behavior, cognition, and emotion, and may affect the development of cognitive abilities and the risk of age-related cognitive changes 
through response to stress, engagement in health behaviors, and cognitively stimulating activities. Investigating the relationship between personality and cognition across the life span can provide valuable information on the role of personality as a protective resource or a source of vulnerability to age-related cognitive decline.

\section{1 | Personality and cognitive performance}

In the current study, we are considering the taxonomy of personality traits organized around five broad dimensions from Big Five/Five-Factor Model (FFM), which includes Openness, Conscientiousness, Extraversion, Agreeableness and Neuroticism (McCrae, 2010; McCrae \& John, 1992). Personality traits are considered to be relatively enduring patterns of thoughts, feelings, and behaviors that distinguish individuals from one another (Roberts \& Mroczek, 2008). Both personality and cognitive ability are core aspects of adult behavior and functioning, and previous research has found relations between these two major constructs, despite some inconsistencies.

For instance, Extraversion has been positively (Ackerman \& Heggestad, 1997; Austin et al., 2002; Schaie, Willis, \& Caskie, 2004) and negatively related to intelligence, reasoning and verbal ability (Baker \& Bichsel, 2006; Graham \& Lachman, 2014; Mccrae, 1987; Moutafi et al., 2003; Moutafi, Furnham, \& Paltiel, 2005; Soubelet \& Salthouse, 2011; Wolf \& Ackerman, 2005). Meta-analysis indicates, however, that regardless of whether the association is positive or negative, it is very weak (Wolf \& Ackerman, 2005). Some researchers have suggested that the association between cognition and Extraversion is domain-specific, such that individuals high in Extraversion perform better on speed-based tasks, but worse on tasks that require effortful processing and reasoning (Luchetti, Terracciano, Stephan, \& Sutin, 2016).

Conscientiousness has shown bidirectional associations with cognitive performance. Some studies found positive associations with the speed of processing (Graham \& Lachman, 2014; Soubelet \& Salthouse, 2011; Stock \& Beste, 2015), and short-term memory (Baker \& Bichsel, 2006; Maldonato et al., 2017). However, Conscientiousness is frequently negatively associated with abstract reasoning or fluid intelligence (Allik \& Realo, 1997; Chamorro-Premuzic \& Fumham, 2006; Chamorro-Premuzic \& Furnham, 2008; Moutafi et al., 2003, 2005; Moutafi, Furnham, \& Paitiel, 2004). Agreeableness is not typically associated with cognition (Ackerman \& Heggestad, 1997; Austin et al., 2002; Baker \& Bichsel, 2006; Chapman et al., 2012; Curtis et al., 2015; Furnham, Moutafi, \& Chamorro-Premuzic, 2005; Graham \& Lachman, 2014; Moutafi et al., 2005; Soubelet \& Salthouse, 2011), although some reports found negative associations (e.g., measures of intelligence, spatial orientation, verbal fluency and reaction time) (Baker \& Bichsel, 2006; Graham \& Lachman, 2012; Maldonato et al., 2017; Schaie et al., 2004).

The strongest and most consistent finding is that Openness is positively associated with cognitive abilities, followed by Neuroticism being negatively linked to cognitive performance, as shown in a previous meta-analysis (Ackerman \& Heggestad, 1997), and several subsequent studies (Ashton, Lee, Vernon, \& Jang, 2000; Baker \& Bichsel, 2006; Chamorro-Premuzic, Furnham, \& Petrides, 2006; ChamorroPremuzic, Moutafi, \& Furnham, 2005; Graham \& Lachman, 2012, 2014; Maldonato et al., 2017; Mccrae, 1987; Moutafi et al., 2003, 2005; Schaie et al., 2004; Sharp, Reynolds, Pedersen, \& Gatz, 2010; Soubelet \& Salthouse, 2011).

Openness-Fluid-Crystallized-Intelligence (OFCI) is a developmental model integrating Openness, fluid (Gf) and crystallized (Gc) intelligence (Ziegler, Danay, Heene, Asendorpf, \& Bühner, 2012), and has been tested in younger and older adults (Ziegler, Cengia, Mussel, \& Gerstorf, 2015; Ziegler et al., 2012). The OFCI model combines four main components from previous research: environmental enrichment, environmental success, mediation hypotheses, and investment theory. The environmental enrichment hypothesis (Raine, Reynolds, Venables, \& Mednick, 2002) assumes that Openness has a positive longitudinal influence on Gf because individuals scoring higher on Openness are more likely to encounter new learning opportunities. The environmental success hypothesis assumes that Gf positively affects the development of Openness. Individuals with high Gf would have a higher probability of successfully managing new problems, increasing the likelihood that they would continue seeking new situations and thereby increasing their Openness to Experience. In addition, the mediation hypothesis suggests that Openness also influences the development of Gc via the effect on the development of Gf. Therefore, in order to learn, it does not suffice to experience new and stimulating situations, but it is also critical that the new information is actively processed using higher cognitive abilities. Lastly, the OFCI model considers investment theory (Cattel, 1987), which states that Gf positively affects the development of Gc. In the case of older adults, the OFCI model was adapted to accommodate the decline of cognitive abilities with increasing age, and the authors suggest that Openness acts as a buffer, slowing down a cognitive decline (Ziegler et al., 2015).

\subsection{Age, cognition, and personality}

The existence of age-related changes in cognition across the adult life span is well established, with a decrease of performance in several abilities, such as fluid reasoning, memory, and speed of processing, but an increase in language (i.e., vocabulary) (Salthouse, 2004, 2009; Salthouse \& Ferrer-Caja, 2003; Stern et al., 2014). Regarding 
personality, despite its relative stability and the previous idea that personality becomes "set like plaster" by age 30 (i.e., the plaster hypothesis) (Costa \& McCrae, 1994, 1997; Costa, Metter, \& Mccrae, 1994; Roberts \& DelVecchio, 2000; Srivastava, John, Gosling, \& Potter, 2003), there is compelling evidence of changes in personality across adulthood, including in old age.

Cross-sectional and longitudinal studies involving both young and older individuals indicated that an increase in age is associated with higher levels of Agreeableness and Conscientiousness, and lower levels of Neuroticism and, less consistently, Openness and Extraversion (Allemand, Zimprich, \& Hendriks, 2008; Caspi, Roberts, \& Shiner, 2005; Costa \& McCrae, 1997; Helson, Jones, \& Kwan, 2002; McCrae, Martin, \& Costa, 2005; Roberts \& Mroczek, 2008; Roberts, Walton, \& Viechtbauer, 2006; Soubelet \& Salthouse, 2011; Srivastava et al., 2003; Terracciano, McCrae, Brant, \& Costa, 2005; Weiss et al., 2005). Despite this observed age effect, it is relevant to consider that major life events can have an impact on personality traits, and are, therefore, confounded with age, since they occur in different phases of life. For instance, a study analyzed approximately 14.700 adults and found specific effects of some major life events (e.g., first job, marriage, childbirth, separation, divorce, and retirement) on different personality traits (Specht et al., 2011). In addition, a framework to better understand personality development across adulthood (TESSERA) has been recently proposed. The framework posits that long-term personality development occurs due to repeated short-term, situational processes. For instance, on a "micro-level," there are triggering situations (T), expectancies (E), states and state expressions (SS), and reactions (RA) that lead to the development of the respective traits on a "macro-level" (for a review, see Wrzuz \& Roberts, 2017).

Little research has examined age effects on personalitycognition relations, and it is an area of debate. A large study involving individuals from 19 to 96 years old found that personality-cognition relations were very similar among young, middle-aged, and older adults (Soubelet \& Salthouse, 2011). In contrast, a study involving adults from 22 to 84 years old found that age moderated the relationship between Neuroticism and cognition (e.g., reasoning and reaction time) (Graham \& Lachman, 2014). The same authors also reported that the relationship between personality change (over 10 years) and cognition varied by age, such that older adults whose Neuroticism increased had significantly worse reaction times than those who remained stable or decreased in Neuroticism (Graham \& Lachman, 2012). Furthermore, it has been shown that cognition (i.e., fluid reasoning and working memory) can mediate the age-Conscientiousness association, suggesting that Conscientiousness may help to compensate for age differences in cognition (Soubelet, 2011).

\subsection{Gender, cognition, and personality}

Gender differences in cognitive performance are well documented, typically finding that women outperform men on episodic memory and verbal production tasks, whereas men outperform women on tasks assessing visuospatial ability (De Frias, Nilsson, \& Herlitz, 2006; Halpern \& LaMay, 2000; Herlitz, Nilsson, \& Backman, 1997; Voyer, Voyer, \& Bryden, 1995). In the field of personality research, women have consistently scored higher than men on Neuroticism and Agreeableness (Costa, Terracciano, \& McCrae, 2001; Feingold, 1994; Schmitt, Realo, Voracek, \& Allik, 2008), and to some extent, Extraversion (Donnellan \& Lucas, 2008; Feingold, 1994; Weisberg, DeYoung, $\&$ Hirsh, 2011). There are inconsistent findings regarding Extraversion differences across gender: men scored higher than women on some facets of Extraversion (e.g., assertiveness, dominance), but lower on others (sociability, warmth, positive emotionality) (Costa et al., 2001; Feingold, 1994; Schmitt et al., 2008). Gender differences in Conscientiousness and Openness/intellect are less consistent. Some evidence suggests higher Conscientiousness in women (Goodwin \& Gotlib, 2004; Marsh, Nagengast, \& Morin, 2013; Schmitt et al., 2008), and findings are contradictory regarding Openness (Goodwin \& Gotlib, 2004; Marsh et al., 2013; Schmitt et al., 2008). Moreover, others found no gender differences regarding Openness and Conscientiousness at the trait-level, only in the facets of these traits (Costa et al., 2001; Feingold, 1994; Weisberg et al., 2011). For example, within the Openness trait, men scored higher in intellect and ideas, while women scored higher in aesthetics and feelings, as well as in orderliness (a Conscientiousness's facet).

In addition, gender differences in personality have been described as consistent between younger (Feingold, 1994) and older samples (Chapman, Duberstein, Sorensen, \& Lyness, 2007), suggesting that gender does not moderate age differences in personality (Donnellan \& Lucas, 2008; Marsh et al., 2013; Roberts et al., 2006). However, others have found that gender moderates age differences in Neuroticism, Openness, and Agreeableness. For example, a positive association was found for age and Agreeableness in women, and a negative association was found for age and Neuroticism in men, and age and Openness in women (McCrae, Terracciano, \& Personality Profiles of Cultures, 2005; Weisberg et al., 2011). Therefore, there is still a debate regarding whether gender is a moderator of age-related changes in personality. Importantly, to the best of our knowledge, there have been 
no studies on the effect of gender on personality-cognition relations, particularly across the life span.

\section{4 | The present study}

Previous studies found associations between personality and age, and personality and gender; however, these demographic variables are rarely considered relevant when examining the relationship between personality and cognition, indicating a gap in the literature that should be more systematically investigated, particularly considering large datasets across the adult life span. The few studies including large datasets across the life span (Graham \& Lachman, 2014; Soubelet \& Salthouse, 2011) found conflicting evidence when examining age as a moderator of personality-cognition relations (Graham \& Lachman, 2014; Soubelet \& Salthouse, 2011). Furthermore, these studies failed to investigate gender as a moderator, which could be relevant because it can impact on both cognitive (De Frias et al., 2006) and personality scores (Schmitt et al., 2008). Furthermore, if age and gender can influence personality-cognition relations, we cannot rule out the possibility that these demographics could also interact and together affect these relations.

Additionally, it is critical to consider methodological limitations when estimating personality-cognition relations. For instance, using one single test score as a proxy for a cognitive ability can be problematic, which can both over- and under-estimate these correlations, confounding the results in the literature (Reeve, Meyer \& Bonaccio, 2006). For instance, general and narrow cognitive abilities can present different associations with personality measures, which may not be psychometrically optimal or comprehensive. These measurement limitations could be overcome by assessing several cognitive domains using multiple well-established cognitive measures.

In order to address the gaps in the literature, the current study has two aims: (1) investigate personality-cognition associations across the adult life span; and (2) test whether age and gender moderate personality-cognition relations. These aims were investigated taking into account methodological advantages: (a) different populations (i.e., two cohorts), (b) relatively large sample sizes $(>400)$, (c) wide age range (young, middle-age and older adults), and (d) cognitive domains based on multiple measures.

\section{2 | METHODS}

\subsection{Samples and recruitment}

The current report is based on two samples. Sample 1 was derived from our ongoing studies at Columbia University
Medical Center: the Reference Ability Neural Network (RANN) study and the Cognitive Reserve (CR) study (Habeck et al., 2016; Stern, 2009; Stern et al., 2014). Sample 2 was derived from the Nathan Kline Institute-Rockland Sample Initiative (NKI-RSI), a community-ascertained life span sample (Nooner et al., 2012). Participants were recruited using established random market mailing procedures, as well as posting of materials in local shops, community centers and meeting places for NKI-RSI. Written informed consent was obtained from all participants prior to any study participation.

\subsection{1 | Sample 1}

In the initial telephone screening, participants who met basic inclusion criteria (i.e., right-handed, English speaking, no psychiatric or neurological disorders, and normal or corrected-to-normal vision) were further screened in person with structured medical and neuropsychological evaluations to ensure that they had no neurological or psychiatric conditions, cognitive impairment or contraindication for MRI scanning. Global cognitive functioning was assessed with the Mattis Dementia Rating Scale (Lucas et al., 1998); on which a minimum score of 135 was required for retention in the study. In addition, any performance on the cognitive test battery that was indicative of mild cognitive impairment was grounds for exclusion. The studies were approved by the Internal Review Board of the College of Physicians and Surgeons of Columbia University. Additional details about procedures can be found in previous reports (Habeck et al., 2016; Salthouse et al., 2015; Stern, 2009; Stern et al., 2014).

\subsection{2 | Sample 2}

The study included residents of Rockland, Bergen, Orange and Westchester counties, aged 6-85, who were fluent in English. General NKI-RSI exclusions were assessed over a screening phone call or determined at the time of study participation by the research team and included chronic or significant medical illness, serious neurological or metabolic disorders, contraindication for MRI scanning, or inability to ambulate independently. Other exclusionary criteria included any psychiatric condition, which was determined through self-report at screening or study visit via diagnostic interview (SCID-I/NP) (First, Spitzer, Gibbon, \& Williams, 2002).

In addition, individuals with an estimated full score IQ below 70 in the Wechsler Abbreviated Scale of Intelligence 2nd Edition (WASI-II) (Wechsler, 2011) were excluded from the study. This study is in compliance with the Columbia University Institutional Review Board. A more detailed description of this study can be found in (Colvin et al., 2018; Nooner et al., 2012). Besides the initial screening, we only 
included participants with available data on personality and a minimum of cognitive tests enough to calculate one cognitive domain (e.g., reasoning, language, memory or speed of processing).

\section{2 | Measures}

\subsection{1 | Personality}

In Sample 1, personality was measured using the 50-item Big Five scale from the International Personality Item Pool (IPIP), to evaluate five major dimensions of personality: Openness to Experience, Conscientiousness, Extraversion, Agreeableness, and Neuroticism (reversed Emotional Stability) (Goldberg, 1999). Participants rated themselves on a 5-point scale ranging from "Strongly Agree" to "Strongly Disagree" with respect to how well each statement described them. In the sample included for analysis, we identified $0.03 \%$ of item-level missing data in the questionnaire. We computed prorated values by averaging the available items in each personality dimension subscale that had missing values (Schafer \& Graham, 2002). We allowed the maximum of two items missing in each personality dimension subscale for each participant.

In Sample 2, personality was measured through the NEO Five-Factor Inventory (NEO-FFI-3), which included the 60 item scale to assess the same five major dimensions of a personality mentioned above. Similarly, to the IPIP, participants were asked to select the response that best represents their opinion on a 5-point scale ranging from "Strongly Agree" to "Strongly Disagree" (McCrae \& Costa, 2010).

\subsection{2 | Cognition}

Each participant underwent an extended cognitive evaluation. Based on previous factor analysis (Salthouse et al., 2015; Soubelet \& Salthouse, 2011) we created four cognitive domains in Sample 1: reasoning, language, memory, and speed of processing. In order to create similar cognitive domains, we applied the Principal Axis Factor (PAF) analysis to Sample 2, in which the items loaded onto the same cognitive factors (Figure S1). First, we performed a parallel analysis to determine the number of factors within our neuropsychological tasks. We then examined the structure, loadings and statistical fit parameters of the Three- and FiveFactor Models. Lastly, to examine the robustness of the extracted factor structure independent of any age effects, we performed the same PAF analysis after residualizing all neuropsychological task performances with regards to age. The analysis was performed in $R$ using the psych (Revelle, 2019) and lavaan (Rosseel, 2012) packages.
In Sample 1, the cognitive domains included the following tests: Reasoning: Wechsler Adult Intelligence Scale (WAIS-III) Matrix Reasoning, Letter-number Sequencing, and Block Design test (Wechsler, 1997); Language: WAISIII Vocabulary test, the Wechsler Test of Adult Reading (WTAR) (Wechsler, 2001), and the American National Adult Reading Test (AMNART) (Grober, Sliwinski, \& Korey, 1991); Memory: Selective Reminding Test (SRT); last trial, continuous long-term retrieval and last retrieval (Buschke \& Fuld, 1974); Speed of Processing: WAIS-III Digit-symbol (digit coding test), Stroop Color Naming test (Golden, 1975), and Trail Making Test (TMT)-A (time) (Reitan, 1978).

Based on the PAF analysis and the measures available in Sample 2, efforts were made to include the most similar tests in each cognitive domain, as following: Reasoning: WASI-II Matrix Reasoning and Block Design tests (Wechsler, 2011), and the TMT Number-Letter Switching ("TMT-B like" from Delis-Kaplan Executive Functioning System (D-KEFS) (Delis, Kaplan \& Framer, 2001); Language: WASI-II Vocabulary test, and the Wechsler Individual Achievement Test--2nd Edition Abbreviated (WIAT-IIA) Word Reading and Spelling tests (Wechsler, 2005); Memory: Rey Auditory Verbal Learning Test (RAVLT) (Schmidt, 1996), sum of the five learning trials, list B and delayed recall (Schmidt, 1996); Speed of Processing: D-KEFS "Stroop" like task, the Color Naming (time) and Inhibition (time) tests (Delis, Kaplan \& Kramer, 2001).

\section{3 | Statistical analysis}

\subsection{1 | Data description and regression models}

Demographics characteristics and IQ scores of the participants were presented with means, standard deviation or percentage; and differences across the age groups were tested using analyses of variance (ANOVA), or Pearson chi-squared test. In order to assess the relationship between personality and cognition for each sample, we used the structural equation model (SEM) as depicted in Figure 1. In defining cognition, four cognitive abilities were formed from a priori selected variables, and general cognitive ability was defined as the second-order latent variable of the four cognitive abilities. In addition, we fitted additional models (Figure S2) in which personality predicted general cognitive ability (instead each of the cognitive abilities separated), in order to investigate associations between the general cognitive factor and personality. We had to create a separate model to fit general cognitive ability predictions since the models would not converge if these predictions were included in the same model with the predictions of each of the cognitive abilities. Regarding the estimation method, full information maximum 
(a) Sample 1

Age

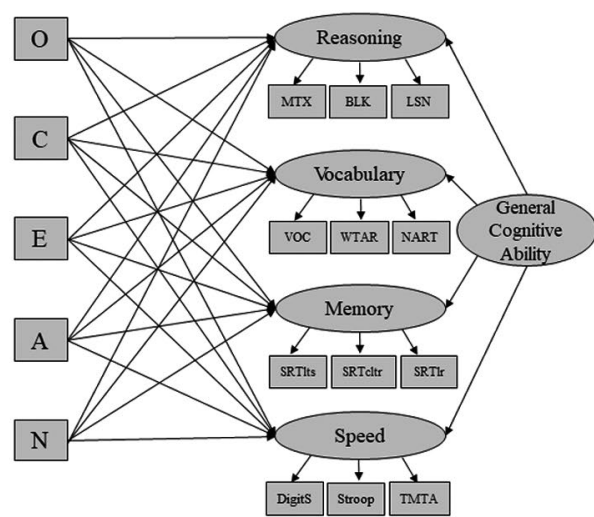

(b) Sample 2

Age Gender

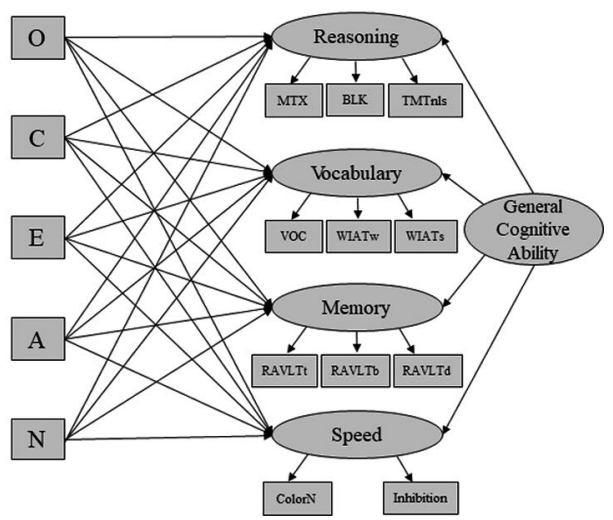

FI G U RE 1 Structural Equation Models for each Sample. In de models, age and gender are linked (through regression paths) to all cognitive abilities. All predictors (age, gender and personality) were allowed to correlate. BLK = Block Design; ColorN = Color Naming; DigitS = DigitSymbol; LSN = Letter-number Sequencing; NART = National Adult Reading Test; MTX = Matrix Reasoning; RAVLT = Rey Auditory Verbal Learning Test ( $\mathrm{t}=$ total five learning trials; $\mathrm{b}=$ list $\mathrm{B} ; \mathrm{d}=$ delayed recall); SRT = Selective Reminding Test; TMTA = Trail Making Test part A; TMT-nls = Trail Making Test Number-Letter Switching; VOC $=$ Vocabulary; WIAT $=$ Wechsler Individual Achievement Test $(\mathrm{w}=$ word reading; $\mathrm{s}=$ spelling); WTAR $=$ Wechsler Test of Adult Reading

likelihood (FIML) was used to allow missing values in the models. In addition, all the predictor variables in the models (i.e., personality, age, and gender) were allowed to correlate.

In order to examine associations between personality, cognition, age, and gender, separate SEMs were conducted for each of the personality measures, with age and gender as predictors and cognitive ability as the outcome. Unadjusted standardized regression coefficients from the second-order hierarchical model represent the marginal association of $\operatorname{cog}$ nitive abilities with personality, age, and gender. In addition, the associations between personality and age were described with Pearson correlation coefficients, and the association between personality and gender were presented with standardized regression coefficients. In Model 1 of Figure 1, we investigated the association between personality and cognitive performance by controlling for relevant demographics that can influence personality and cognition (i.e., age and gender), and all the personality variables, in order to control for the other personality traits, and therefore, assess the unique relationship between each personality trait and cognitive ability. In Model 2, we added two-way interaction terms to the previous model in order to examine the potential moderator effect of age or gender in personality-cognition associations. Lastly, in Model 3, we added the three-way interaction term (age, gender, personality) to investigate possible moderation of age and gender (in combination) in the personality-cognition associations. Critically, we evaluated the moderating effect of age and gender separately by each personality trait; therefore, generating five different Models 2 and five different Models 3. Nevertheless, both Models 2 and 3 include the main effects of other personality traits, age, and gender. It was necessary to separate in different models since adding all high-order interactions in one model (i.e., 10 interaction terms for Model 2, and 15 interaction terms for Model 3) could obscure the interaction effects and increase spurious significant high-order interactions. The variables were centered when using the interaction terms. Model fit indices were calculated for each model, including Generalized Least Squares (GLS), Root Mean Square Error of Approximation (RMSEA), Chis-squared, and $p$ values.

In addition, we conducted a mini-metanalysis procedure (Goh, Haal, \& Rosenthal, 2016) in order to examine personality-cognition associations combining results from the two samples. We computed the combined effect size for the weighted means correlations as follows. First, the partial etasquared of the effects of interests were converted to $r$ by taking the square root, reserving the signs of the beta estimates. The $r$ values from the two studies were transformed via Fisher's $z$ transformation, and the weighted $z$ scores were computed as $\bar{z}_{\text {combined }}=\frac{\left(N_{1}-3\right) z_{1}+\left(N_{2}-3\right) z_{1}}{\left(N_{1}-3\right)+\left(N_{2}-3\right)}$. For easier interpretation, the weighted $z$ scores were converted to $\bar{r}_{c}$ via inverse Fisher's $z$ transformation. To summarize $p$ values for the two studies, the Stouffer's $z$ test was conducted as described previously (Goh et al., 2016) and the $p$ values are reported $\left(p_{c}\right)$. The analysis was performed in $R$ using lavaan (Rosseel, 2012) package. Since the primary results of interest are those for the mini-metanalysis, we understand is not necessary to correct the results for multiple comparisons in the individual samples. Our focus on the results of the individual samples is more on the effect-size estimation than on the results' significance. Finally, we reported all measures considered relevant 
for the current study from a larger set of measures administrated in the CR and RANN studies. We state that we reported our sample size selection and criteria for data exclusion.

\section{3 | RESULTS}

A general description of the two samples is provided in Table 1. It was included 422 participants in Sample 1 and 549 in Sample 2. The mean age of the participants in Sample 1 was 54 years, slightly higher than the mean age in Sample 2 (49.5 years). Furthermore, Sample 2 displayed a higher percentage of women, and lower mean education and IQ than Sample 1. When analyzing demographics by age groups, we observed that Sample 2 showed age differences in the percentage of women, education, and IQ scores, while Sample 1 only showed differences in IQ scores.

Table 2 provides correlations between cognitive performance, personality scores, age, and gender, considering the hierarchical model. All cognitive domains were associated with Openness, which was observed for general cognitive ability, language, and memory in both samples, but for speed only in Sample 1, and for reasoning only in Sample 2. In addition, there were negative associations between language and personality, such that in Sample 1 language was associated with Neuroticism, and in Sample 2 language was correlated to Extraversion. Age was negatively correlated with Neuroticism in both cohorts, but correlations with Extraversion and Agreeableness occurred only in Sample 2. There was no association between gender and any personality trait in Sample 1, while in Sample 2 women presented higher scores of Conscientiousness and Agreeableness. Regarding cognitive measures, age effects were similar in the two datasets, indicating a decline of performance as a function of age in general cognitive ability, reasoning, memory, and speed, but an increase of language scores. Lastly, gender was only associated with general cognitive ability in Sample, indicating a better performance in men.

\section{1 | Model 1: Personality- cognition relations}

Model 1 of Figure 1 presented a good fit statistic for both Sample 1 (GFI $=.916$, RMSEA $=.058$, ChiSquared $=257.017, p<.001)$ and Sample $2(\mathrm{GFI}=.937$, RMSEA $=.045$, Chi-Squared $=188.691, p<.001)$. Similarly, good fit statistic was observed for the Model 1 focused in the General Cognitive Ability (GFI $=.837$, RMSEA $=.088$, Chi-Squared $=543.232, p<.001$ ) and Sample 2 (GFI $=.886$, RMSEA $=.067$, ChiSquared $=337.424, p<.001)$.

Table 3 present the pattern of personality-cognition associations in each sample. Openness was positively associated with most cognitive measures, indicating that higher Openness is linked to better general cognitive ability, reasoning, language, and memory. Extraversion was negatively associated with general cognitive ability, reasoning, and language in both samples. In addition, we found specific results for each sample, such as the positive association between Conscientiousness and speed in Sample 1, and the negative association between Neuroticism and both general cognitive ability, and reasoning, in Sample 2 .

T A B L E 1 General description of the samples

\begin{tabular}{|c|c|c|c|c|c|}
\hline & All & Young & Middle age & Older adults & $p$ value \\
\hline Number of subjects & 422 & 106 & 100 & 216 & \\
\hline Age, $M(S D)$, years & $54.0(16.7)$ & $29.3(4.9)$ & $50.5(5.3)$ & $67.7(5.2)$ & $<.001$ \\
\hline Sex, $\%$ of Women & $54.6 \%$ & $50.9 \%$ & $58.6 \%$ & $54.6 \%$ & .54 \\
\hline Education, $M(S D)$, years & $16.2(2.3)$ & $15.8(2.3)$ & $16.2(2.3)$ & $16.4(2.3)$ & .15 \\
\hline Sample 2 & 18-85 years & 18-39 years & 40-59 years & 60-85 years & \\
\hline Number of subjects & 549 & 168 & 181 & 200 & \\
\hline Age, $M(S D)$, years & $49.5(18.8)$ & $25.6(6.1)$ & $49.8(5.7)$ & $69.5(6.1)$ & $<.001$ \\
\hline Sex, $\%$ of Women & $67.9 \%$ & $57.7 \%$ & $80.1 \%$ & $65.5 \%$ & $<.001$ \\
\hline
\end{tabular}

Note: $p$ value refers to the comparison (one-way ANOVA) between young, middle-age, and older adults.

Abbreviations: $M$, Mean; $S D$, Standard Deviation.

${ }^{\mathrm{a}}$ IQ scores based on the American National Reading Test (AMNART).

${ }^{\mathrm{b}}$ IQ scores based on the Wechsler Abbreviated Scale of Intelligence (WASI). 
TA B L E 2 Associations between cognitive abilities, personality, age, and gender

\begin{tabular}{|c|c|c|c|c|c|c|c|}
\hline & $\mathbf{O}$ & $\mathbf{C}$ & $\mathbf{E}$ & $\mathbf{A}$ & $\mathbf{N}$ & Age & Gender \\
\hline General Cognitive Ability & $.23(.001)$ & $-.07(.20)$ & $-.07(.20)$ & $-.01(.80)$ & $.03(.54)$ & $-.67(<.001)$ & $-.12(.01)$ \\
\hline Reasoning & $.21(.65)$ & $-.11(.71)$ & $-.09(.83)$ & $-.02(.87)$ & $.03(.83)$ & $-.47(.03)$ & $-.01(.71)$ \\
\hline Language & $.26(<.001)$ & $-.01(.84)$ & $-.02(.62)$ & $.08(.13)$ & $-.10(.04)$ & $.25(<.001)$ & $-.009(.56)$ \\
\hline Memory & $.13(.01)$ & $-.06(.20)$ & $-.02(.67)$ & $.004(.94)$ & $.02(.65)$ & $-.47(<.001)$ & $.002(.89)$ \\
\hline Age & $-.08(.08)$ & $.05(.22)$ & $.01(.82)$ & $.05(.29)$ & $-.13(.004)$ & - & - \\
\hline Gender & $.06(.16)$ & $.03(.42)$ & $.09(.05)$ & $.08(.07)$ & $.02(.66)$ & - & - \\
\hline \multicolumn{8}{|l|}{ Sample 2} \\
\hline General Cognitive Ability & $.22(<.001)$ & $-.03(.57)$ & $-.009(.86)$ & $-.06(.25)$ & $-.03(.50)$ & $-.46(<.001)$ & $-.03(.65)$ \\
\hline Speed & $.08(.10)$ & $.04(.39)$ & $.07(.14)$ & $-.007(.88)$ & $-.01(.70)$ & $-.38(<.001)$ & $.01(.54)$ \\
\hline Age & $-.06(.16)$ & $.04(.27)$ & $-.13(.002)$ & $.15(<.001)$ & $-.15(<.001)$ & - & - \\
\hline Gender & $.03(.45)$ & $.10(.01)$ & $.04(.29)$ & $.30(<.001)$ & $.01(.79)$ & - & - \\
\hline
\end{tabular}

Note: Associations between cognition, personality, age, and gender represent standardized regression coefficient from unadjusted models. Age and personality associations are presented with Pearson correlations; and personality and gender associations are described with standardized regression coefficients. Reference values for gender: 0 - men; 1 - women. Values for General Cognitive Ability are based on a separate model. Higher speed values reflect better performance. $p$ values are presented in the parentheses and significant results are highlighted in bold $(p<.05)$.

\section{2 | Moderation effects: Models 2 and 3}

Similar to Model 1, both Models 2 and 3 presented a good fit statistics (Tables S1-S4). Table 4 describes the moderators of cognition-personality relations. Regarding Model 2, we observed gender moderations only in Sample 2. Gender moderated the association between Conscientiousness and reasoning, Conscientiousness and general cognitive ability, Openness and memory, and Openness and general cognitive ability. In Model 3 , both age and gender moderated the relationship between Conscientiousness and language in Sample 1.

\section{3 | Meta-analysis summary}

After combining the two samples using the mini-metanalysis procedure (Tables 3 and 4), we found that Openness was associated with general cognitive ability and all four cognitive abilities in Model 1. In addition, Extraversion was negatively associated with general cognitive ability, reasoning, and language; Neuroticism was negatively associated with general cognitive ability and reasoning; and Conscientiousness was positively associated with speed. In Model 2, gender moderated the association between Conscientiousness and general cognitive ability, and Conscientiousness and reasoning, indicating that higher levels of Conscientiousness were associated with better cognitive performance in women, but not in men (Figure 2).

\section{4 | DISCUSSION}

The present study investigated the relations between the FFM of personality and cognitive domains across the adult life span in two independent samples, and whether these relations can be moderated by age and gender. We report two major findings. First, aspects of personality are associated with specific cognitive abilities, and these relations are consistent across the two samples. Openness was positively associated with all cognitive abilities, Conscientiousness was positively associated with speed, Extraversion was negatively associated with general cognitive ability, reasoning and language, and Neuroticism was negatively linked to general cognitive ability and reasoning. Second, age and gender moderation were weak and not consistent across samples. the gender moderations on the association between Conscientiousness and cognitive ability (i.e., reasoning and general cognition) remained significant after applying a meta-analytical procedure across the two samples.

The strongest relation between personality and cognition occurred between Openness and intelligence measures: both fluid (reasoning factor), crystallized (language factor). This 


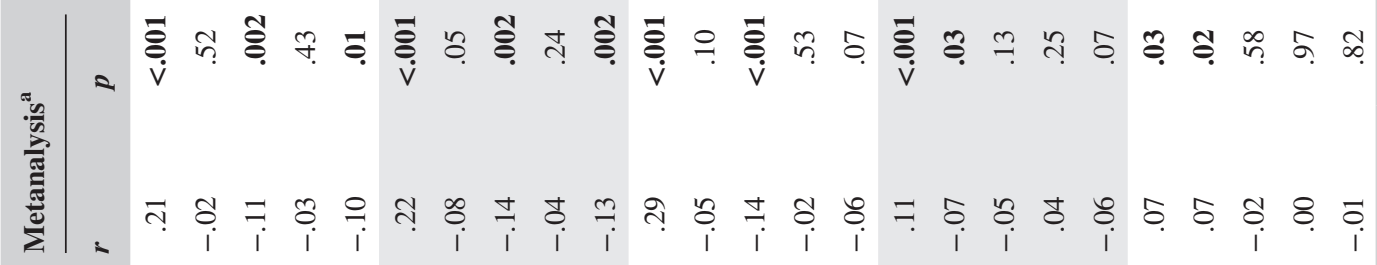

จ

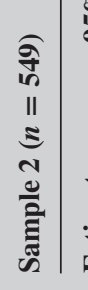

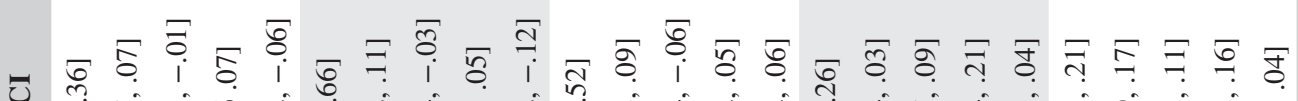

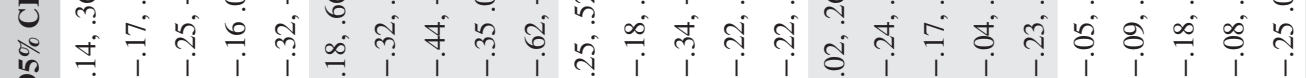

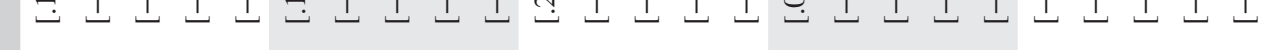

矛

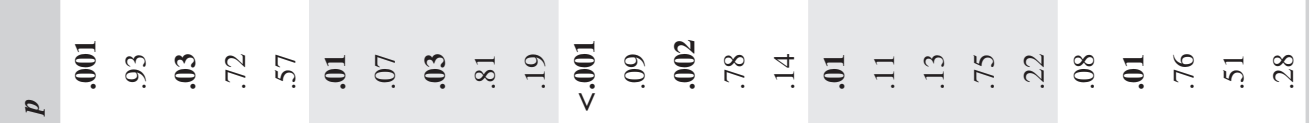

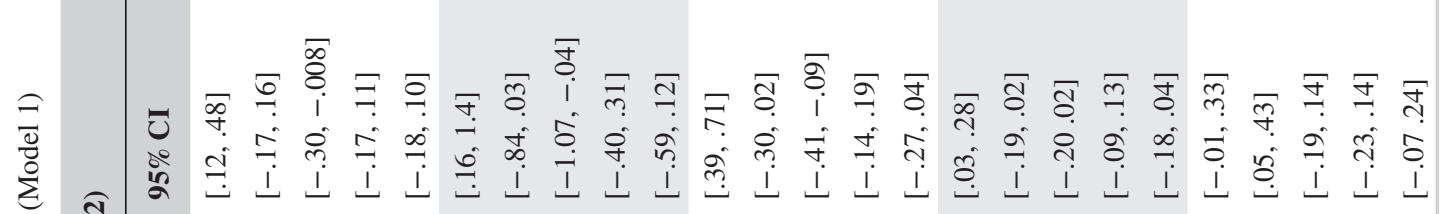

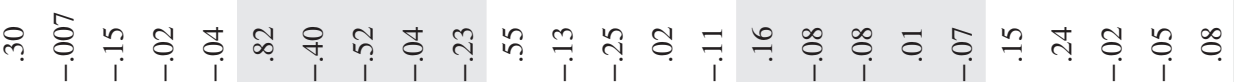

苂
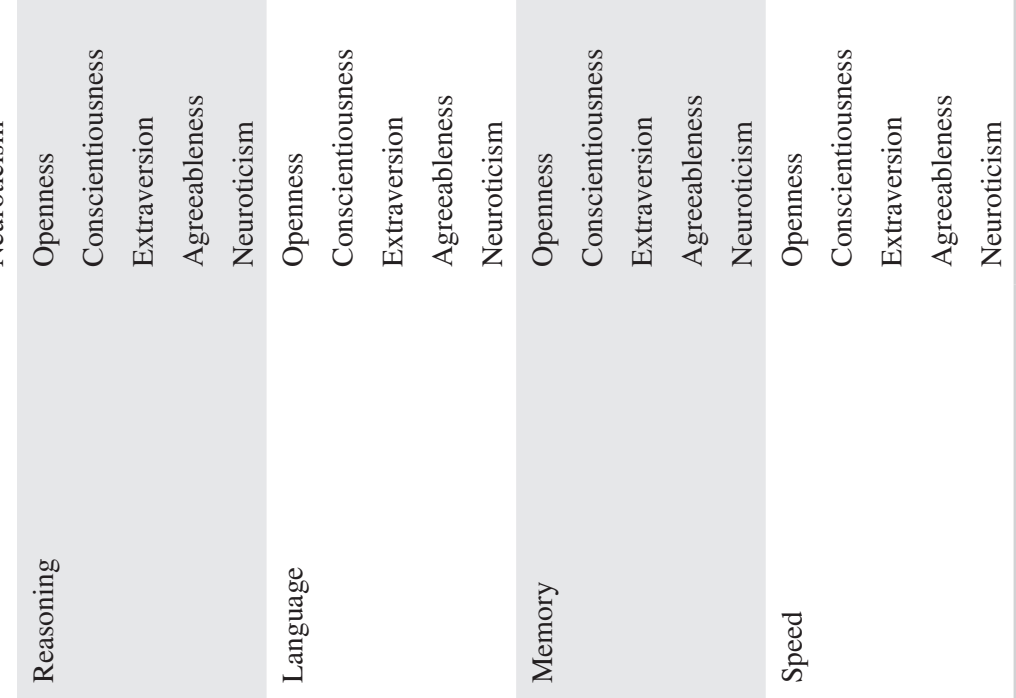

ᄅ্
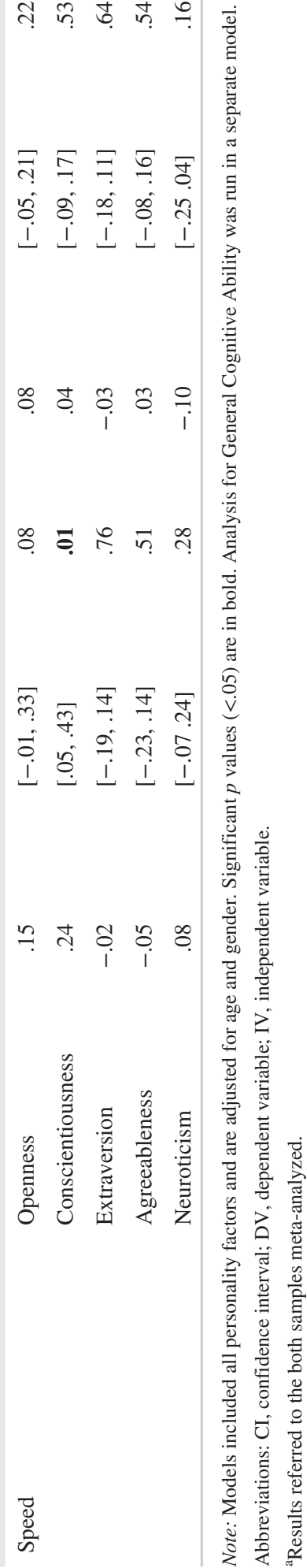
TA B L E 4 Moderators of personality-cognition relations in each sample

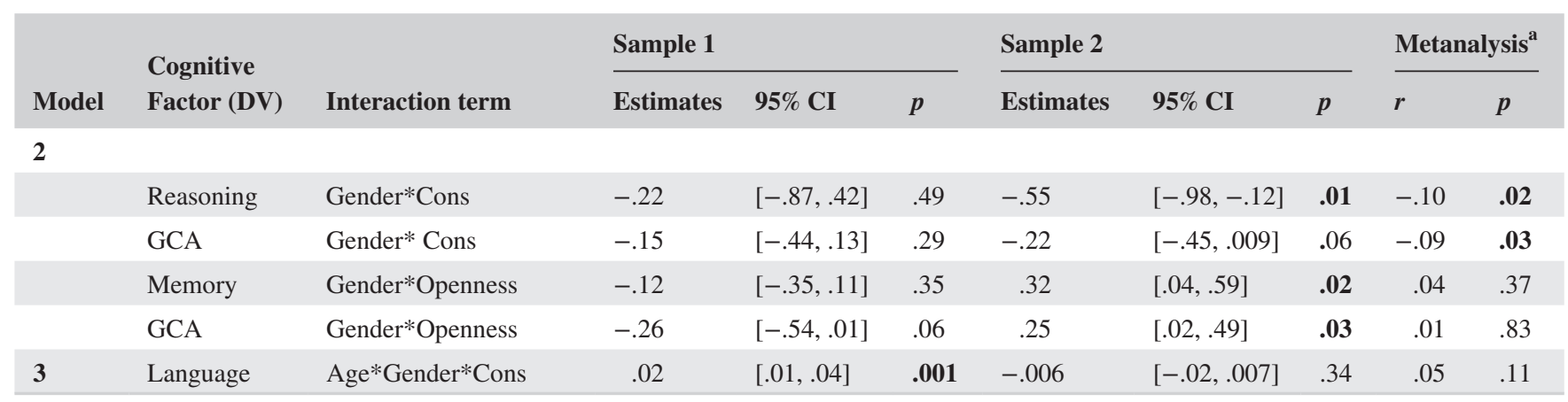

Note: Models are adjusted by age, gender, and the other personality traits. Model 2 included two-way interaction terms in the absent of the 3-way interaction terms, which were included only in the Model 3. Only significant results are displayed in the table. Significant $p$ values (<.05) are in bold. Analysis for General Cognitive Ability was run in a separate model.

Abbreviations: CI, confidence interval; Cons, Conscientiousness; GCA, General Cognitive Ability.

${ }^{a}$ Results referred to the both samples meta-analyzed.

(a) Sample 1

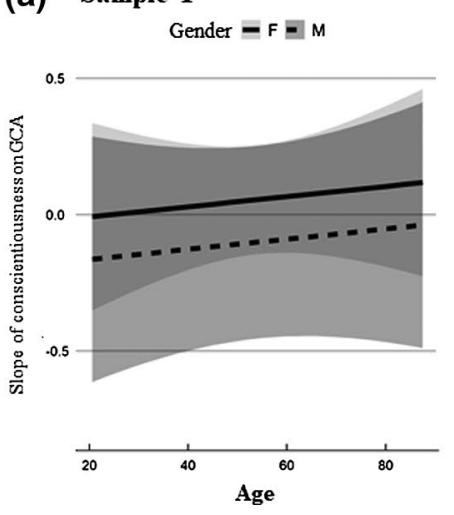

Sample 2

Gender $=\mathrm{F}=\mathrm{M}$

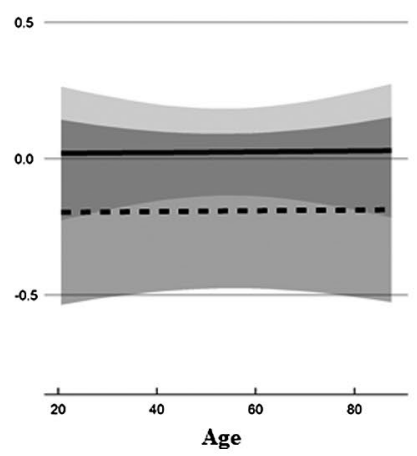

(b) Sample 1

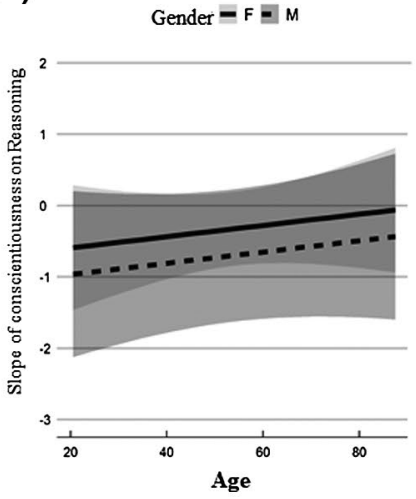

Sample 2

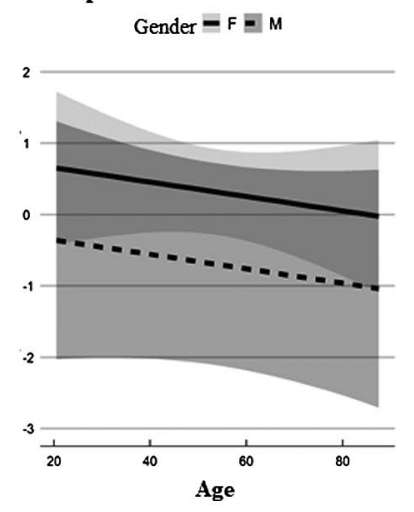

F I G U RE 2 Gender moderation of Conscientiousness-cognition association. (a) refers to gender moderation on Conscientiousness and global cognitive ability (GCA); (b) refers to gender moderation on Conscientiousness and reasoning. $F=$ Female; $M=$ Male

observation has been reported by others and is not surprising since some of the adjectives used to measure Openness have an intellectual connotation, leading researchers to call it the "Intellect factor" (Ackerman \& Heggestad, 1997; Ashton et al., 2000; Baker \& Bichsel, 2006; DeYoung et al., 2005; Schaie et al., 2004; Soubelet \& Salthouse, 2011). We also found that Openness predicted memory performance, similar to previous research (Schaie et al., 2004; Soubelet \& Salthouse, 2011; Terry, Puente, Brown, Faraco, \& Miller, 2013), which remained significant when applying a meta-analysis to both samples. Although we did not find that Openness was associated with speed in either sample, this relationship was significant after applying the meta-analytical procedure, in line with previous reports (Sharp et al., 2010; Soubelet \& Salthouse, 2011), but not others (Graham \& Lachman, 2014; Wettstein, Tauber, Kuzma, \& Wahl, 2017). These findings are consistent with the OFCI model (Ziegler et al., 2012), suggesting that individuals with higher levels of Openness may be more likely to spend time exploring intellectual pursuits, which can influence cognitive performance.
Associations between Extraversion and cognition have been inconsistently noted. Previous meta-analysis indicates that the Extraversion-intelligence relationship varies in magnitude and direction as a function of study, depending on the instruments used (Wolf \& Ackerman, 2005). In the current study, Extraversion was negatively associated with language, reasoning and general cognitive ability in both samples. These results are in line with previous studies focused on FFM that also included young, middle and older individuals (Graham \& Lachman, 2014; Soubelet \& Salthouse, 2011), but are inconsistent with another report (Schaie et al., 2004). In addition, Baker and colleagues found negative associations between Extraversion and crystallized knowledge only for young adults, but not for older individuals (Baker \& Bichsel, 2006). Furthermore, others have suggested that introverted individuals may display slower performance, because they are more likely to take time to think thoroughly about a task (Baker \& Bichsel, 2006; Wolf \& Ackerman, 2005). We hypothesize that the association between Extraversion and cognition may differ based on the extent to which better scores 
are related to the accuracy, effortful processing or speed (Chamorro-Premuzic \& Fumham, 2006; Luchetti et al., 2016).

In addition, we only found a positive association between Conscientiousness, and speed of processing in one sample, in line with previous reports (Graham \& Lachman, 2014; Soubelet \& Salthouse, 2011; Stock \& Beste, 2015), which remained significant in the meta-analysis considering the two samples. This finding may be related to the observation that highly conscientious people tend to be more organized, goal-directed and present self-discipline, with evidence of a more efficient step-by-step processing strategy to achieve a goal, which may contribute to a faster performance (Stock \& Beste, 2015).

Our study supports the claim that higher levels of Neuroticism are associated with poorer cognitive performance in healthy adults, in line with several cross-sectional studies (Graham \& Lachman, 2014; Saylik, Szamentat, Cheeta, 2018; Soubelet \& Salthouse, 2011), and longitudinal findings that indicate higher Neuroticism is associated with greater cognitive decline in older adults (Luchetti et al., 2016; Waggel et al., 2015), major depression, and incident Alzheimer's disease (for a review see Terracicano \& Sutin, 2019). These findings are consistent with the "mental noise hypothesis," which suggests that individuals with higher Neuroticism experience more mental noise due to higher levels of anxiety, stress, worry-related thoughts, aspects that contribute to distractions and can impair cognitive performance (Curtis et al., 2015; Robinson \& Tamir, 2005; Robison, Gath, \& Unsworth, 2017). Another hypothesis, particularly for older individuals, is that the prolonged arousal experienced by individuals with higher Neuroticism causes neural damage over time (Curtis et al., 2015).

We did not find any associations between Agreeableness and cognition in any sample, consistent with other reports (Ackerman \& Heggestad, 1997; Austin et al., 2002; Baker \& Bichsel, 2006; Chapman et al., 2012; Curtis et al., 2015; Furnham et al., 2005; Graham \& Lachman, 2014; Moutafi et al., 2005; Soubelet \& Salthouse, 2011). However, others have described negative associations (Baker \& Bichsel, 2006; Graham \& Lachman, 2012; Maldonato et al., 2017; Schaie et al., 2004), suggesting that better cognitive abilities decrease the need for pleasing others and are thus related to lower levels of Agreeableness (Baker \& Bichsel, 2006; Segel-Karpas \& Lachman, 2016). In addition, highly agreeable people may rely on their social skills, rather than on cognitive performance as the main avenue for achievements, which possibly contributes to the lack of association between Agreeableness and cognition (Segel-Karpas \& Lachman, 2016).

We found that age did not moderate personality-cognition relations, in line with a large study across adulthood (Soubelet $\&$ Salthouse, 2011), but not consistent with another study that observed age moderation in some of the personality-cognition associations (Graham \& Lachman, 2014). Despite gender did not consistently moderate personality-cognition relations across the samples, the meta-analysis showed that gender moderated cognition-Conscientiousness. Therefore, the pattern observed in Sample 2 was extended when considering the two samples together, indicating that higher levels of Conscientiousness are associated with better general cognitive ability and reasoning in women, but not in men.

The present study had several strengths. First, we analyzed personality-cognition relations across the adult life span using two different cohorts, including large sample sizes and a wide age range. Second, each cognitive domain was created based on multiple cognitive tests, which minimizes the bias of a specific task. In each sample, the cognitive tests were grouped based on a statistical method (i.e., factor analysis), in order to reassure the tasks were measuring the same cognitive domain. Third, the personality scales across cohorts (IPIP vs. NEOFFI) are both based on the Five-Factor Model and have been demonstrated to be highly correlated (Gow, Whiteman, Pattie $\&$ Deary, 2005). Fourth, we conducted a mini-metanalysis procedure that allowed us to examine personality-cognition relations combining data from the two samples, thus optimizing the power of our analysis. Lastly, we were able to examine the unique association of each trait to each cognitive factor, since our models controlled for the other personality traits, age, and gender, which are critical demographics that can interfere in cognitive performance and personality.

Despite its contributions, our study does have important limitations. We used a cross-sectional design to investigate personality-cognition relations, which does not allow us to make directional conclusions, infer causality, and exclude cohort effects. Future work involving longitudinal data will allow for testing causal models to further understand the associations identified. Personality data was examined only at the trait-level, and not sub-factor level (e.g., facets), which limits the interpretation of the results, and may account for some variability in the findings. Future work should include facets more systematically, and not only traits in order to better understand personality-cognition relations (Graham \& Lachman, 2014). In addition, both samples were highly educated, which limits the external validity of the study. Additional research on personality-cognition relations involving a wider educational range is relevant, especially because educational attainment can moderate personality-cognition relations (Rammstedt et al., 2016). Finally, it is possible that the differences between samples may reflect the different cognitive and personality instruments used in each sample. Previous research has shown two major subfactors within each of the Big Five factors (De Young, Quilty \& Peterson, 2007); however, the two factors are better represented in the NEO-FFI than in the IPIP-50. For instance, in the IPIP-50, the Openness scale is tilted more toward intellect than Openness to Experience, 
and the Conscientiousness scale is strongly biased to orderliness rather than industriousness. This difference across instruments suggests that the IPIP-50 presents a narrower personality assessment than the NEO-FFI, which may influence associations with cognitive ability.

In conclusion, this study extends previous findings and provides novel information on personality-cognition relations. First, we observed in two independent samples that personality was associated with cognitive performance, particularly Openness, and Extraversion, and to some extent Conscientiousness and Neuroticism. We found that crystallized and fluid intelligence (i.e., language and reasoning, respectively) were the cognitive abilities most consistently linked with personality; however, memory and speed were also associated. In addition, our findings suggest that age and gender do not consistently moderate personality-cognition relations, however, we found that gender may moderate Conscientiousness-reasoning associations, indicating that these relations may be more complex than previous research has suggested. Investigating the complexity of personality-cognition relations can help to elucidate patterns of behavior throughout the life span that might be a protective resource or a source of vulnerability to cognitive functioning, especially later in life.

\section{ACKNOWLEDGMENTS}

The authors would like to thank Maria A. Pleshkevich and Reshma S. Babukutty for their excellent assistance.

The authors disclosed receipt of the following financial support for the research, authorship, and/or publication of this article: This work was supported by grants R01AG026158 and RF1AG038465 from the National Institute on Aging.

\section{CONFLICT OF INTEREST}

The author(s) declared no potential conflicts of interest with respect to the research, authorship, and/or publication of this article.

\section{ORCID}

Sharon S. Simon (D) https://orcid.org/0000-0003-2603-6215

\section{REFERENCES}

Ackerman, P. L., \& Heggestad, E. D. (1997). Intelligence, personality, and interests: Evidence for overlapping traits. Psychological Bulletin, 121, 219-245. https://doi.org/10.1037/0033-2909.121.2.219

Allemand, M., Zimprich, D., \& Hendriks, A. A. (2008). Age differences in five personality domains across the life span. Developmental Psychology, 44, 758-770. https://doi. org/10.1037/0012-1649.44.3.758

Allik, J., \& Realo, A. (1997). Intelligence, academic abilities, and personality. Personality and Individual Differences, 23, 809-814. https://doi.org/10.1016/S0191-8869(97)00103-7

Ashton, M. C., Lee, K., Vernon, P. A., \& Jang, K. L. (2000). Fluid intelligence, crystallized intelligence, and the Openness/intellect factor. Journal of Research in Personality, 34, 198-207. https://doi. org/10.1006/jrpe.1999.2276

Austin, E. J., Deary, I. J., Whiteman, M. C., Fowkes, F., Pedersen, N. L., Rabbitt, P., .. McInnes, L. (2002). Relationships between ability and personality: Does intelligence contribute positively to personal and social adjustment? Personality and Individual Differences, 32, 1391-1411. https://doi.org/10.1016/S0191-8869(01)00129-5

Baker, T. J., \& Bichsel, J. (2006). Personality predictors of intelligence: Differences between young and cognitively healthy older adults. Personality and Individual Differences, 41, 861-871. https://doi. org/10.1016/j.paid.2006.02.017

Bogg, T., \& Roberts, B. W. (2013). The case for Conscientiousness: Evidence and implications for a personality trait marker of health and longevity. Annals of Behavioral Medicine, 45, 278-288. https:// doi.org/10.1007/s12160-012-9454-6

Buschke, H., \& Fuld, P. A. (1974). Evaluating storage, retention, and retrieval in disordered memory and learning. Neurology, 24, 10191025. https://doi.org/10.1212/WNL.24.11.1019

Caspi, A., Roberts, B. W., \& Shiner, R. L. (2005). Personality development: Stability and change. Annual Review of Psychology, 56, 453-484. https://doi.org/10.1146/annurev.psych.55.090902.141913

Cattell, R. B. (1987). Intelligence: Its Structure, Growth and Action. New York: North-Holland.

Delis, D. C., Kaplan, E., \& Kramer, J. H. (2001). Delis-Kaplan Executive Function System (DKEFS). San Antonio: Psychological Corporation.

Chamorro-Premuzic, T., \& Fumham, A. (2006). Intellectual competence and the intelligent personality: A third way in differential psychology. Review of General Psychology, 10, 251-267. https://doi. org/10.1037/1089-2680.10.3.251

Chamorro-Premuzic, T., \& Furnham, A. (2008). Personality, intelligence and approaches to learning as predictors of academic performance. Personality and Individual Differences, 44(7), 1596-1603. https://doi.org/10.1016/j.paid.2008.01.003

Chamorro-Premuzic, T.,Furnham,A.,\&Petrides, K.V.(2006).Personality and Intelligence: The Relationship of Eysenck's Giant Three with Verbal and Numerical Ability. Journal of Individual Differences, 27, 147-150. https://doi.org/10.1027/1614-0001.27.3.147

Chamorro-Premuzic, T., Moutafi, J., \& Furnham, A. (2005). The relationship between personality traits, subjectively-assessed and fluid intelligence. Personality and Individual Differences, 38, 1517-1528. https://doi.org/10.1016/j.paid.2004.09.018

Chapman, B. P., Duberstein, P. R., Sorensen, S., \& Lyness, J. M. (2007). Gender differences in Five Factor Model personality traits in an elderly cohort: Extension of robust and surprising findings to an older generation. Personality and Individual Differences, 43, 1594-1603. https://doi.org/10.1016/j.paid.2007.04.028

Chapman, B., Duberstein, P., Tindle, H. A., Sink, K. M., Robbins, J., Tancredi, D. J., ... Gingko Evaluation of Memory Study, I. (2012). Personality predicts cognitive function over 7 years in older persons. American Journal of Geriatric Psychiatry, 20, 612-621. https://doi. org/10.1097/JGP.0b013e31822cc9cb

Colvin, L. E., Malgaroli, M., Chapman, S., Mackay-Brandt, A., \& Cosentino, S. (2018). Mood and Personality Characteristics are Associated with Metamemory Knowledge Accuracy in a Community-Based Cohort of Older Adults. JINS, 24(5), 498-510. https://doi.org/10.1017/S1355617717001345

Costa, P. T., \& McCrae, R. R. (1994). Set like plaster: Evidence for the stability of adult personality. In T. F. Heatherton \& J. L. Weinberger (Eds.), Can personality change? Washington 
(pp. 21-40). DC: American Psychological Association. http://dx. doi.org/10.1037/10143-002

Costa, P. T. J., \& McCrae, R. R. (1997). Longitudinal stability of adult personality. In R. Hogan, J. Johnson, \& S. Briggs (Eds.), Handbook of personality psychology (pp. 269-290). https://doi.org/10.1016/ B978-0-12-134645-4.X5000-8

Costa, P. T., Metter, E. J., \& Mccrae, R. R. (1994). Personality stability and its contribution to successful aging. Journal of Geriatric Psychiatry, 27, 41-59.

Costa, P. T., Terracciano, A., \& McCrae, R. R. (2001). Gender differences in personality traits across cultures: Robust and surprising findings. Journal of Personality and Social Psychology, 81, 322-331. https://doi.org/10.1037/0022-3514.81.2.322

Curtis, R. G., Windsor, T. D., \& Soubelet, A. (2015). The relationship between Big-5 personality traits and cognitive ability in older adults-a review. Aging, Neuropsychology, and Cognition, 22, 42-71. https://doi.org/10.1080/13825585.2014.888392

De Frias, C. M., Nilsson, L. G., \& Herlitz, A. (2006). Sex differences in cognition are stable over a 10-year period in adulthood and old age. Aging Neuropsychology and Cognition, 13, 574-587. https:// doi.org/10.1080/13825580600678418

DeYoung, C. G., Peterson, J. B., \& Higgins, D. M. (2005). Sources of Openness/intellect: Cognitive and neuropsychological correlates of the fifth factor of personality. Journal of Personality, 73, 825-858. https://doi.org/10.1111/j.1467-6494.2005.00330.x

DeYoung, C. G., Quilty, L. C., \& Peterson, J. B. (2007). Between facets and domains: 10 Aspects of the Big Five. Journal of Personality and Social Psychology, 93, 880-896.

Donnellan, M. B., \& Lucas, R. E. (2008). Age differences in the Big Five across the life span: Evidence from two national samples. Psychology of Aging, 23, 558-566. https://doi.org/10.1037/a0012897

Feingold, A. (1994). Gender differences in personality: A meta-analysis. Psychological Bulletin, 116, 429-456. https://doi. org/10.1037/0033-2909.116.3.429

First, M. B., Spitzer, R. L., Gibbon, M., \& Williams, J. B. W. (2002). Structured Clinical Interview for DSM-IV Axis I Disorders, Research Version, Non-patient Edition. New York, NY: SCID-I/NP.

Furnham, A., Moutafi, J., \& Chamorro-Premuzic, T. (2005). Personality and intelligence: Gender, the big five, self-estimated and psychometric intelligence. International Journal of Selection and Assessment, 13, 11-24. https://doi.org/10.1111/j.0965-075X.2005.00296.X

Goh, J. X., Haal, J. A., \& Rosenthal, R. (2016). Mini meta-analysis of your own studies: Some arguments on why and a primer on how. Social and Personality Psychology Compass, 10, 535-549. https:// doi.org/10.1111/spc3.12267

Goldberg, L. R. (1999). A broad-bandwidth, public-domain, personality inventory measuring the lower-level facets of several five-factor models. In I. Mervield, I. J. Deary, F. De Fruyt, \& F. Ostendorf (Eds.), Personality psychology in Europe (Vol. 7, pp. 7-28). Tilburg, The Netherlands: Tilburg University Press.

Golden, C. J. (1975). A group version of the Stroop Color and Word Test. Journal of Personality Assessment, 39, 386-388. https://doi. org/10.1207/s15327752jpa3904_10

Goodwin, R. D., \& Gotlib, I. H. (2004). Gender differences in depression: The role of personality factors. Psychiatry Research, 126, 135 142. https://doi.org/10.1016/j.psychres.2003.12.024

Gow, A. J., Whiteman, M. C., Pattie, A., \& Deary, I. J. (2005). Goldberg's "IPIP" Big-Five markers: Internal consistency and concurrent validation in Scotland. Personality and Individual Differences, 39, 317-329. https://doi.org/10.1016/j.paid.2005.01.011
Graham, E. K., \& Lachman, M. E. (2012). Personality stability is associated with better cognitive performance in adulthood: Are the stable more able? Journals of Gerontology Series B, Psychological Sciences and Social Sciences, 67, 545-554. https://doi.org/10.1093/ geronb/gbr149

Graham, E. K., \& Lachman, M. E. (2014). Personality traits, facets and cognitive performance: Age differences in their relations. Personality and Individual Differences, 59, 89-95. https://doi. org/10.1016/j.paid.2013.11.011

Grober, E., Sliwinski, M., \& Korey, S. R. (1991). Development and validation of a model for estimating premorbid verbal intelligence in the elderly. Journal of Clinical and Experimental Neuropsychology, 13, 933-949. https://doi.org/10.1080/01688639108405109

Habeck, C., Gazes, Y., Razlighi, Q., Steffener, J., Brickman, A., Barulli, D., ... Stern, Y. (2016). The reference ability neural network study: Life-time stability of reference-ability neural networks derived from task maps of young adults. NeuroImage, 125, 693-704. https://doi. org/10.1016/j.neuroimage.2015.10.077

Halpern, D. F., \& LaMay, M. L. (2000). The smarter sex: A critical review of sex differences in intelligence. Educational Psychology Review, 12, 229-246. https://doi.org/10.1023/A:1009027516424

Helson, R., Jones, C., \& Kwan, V. S. (2002). Personality change over 40 years of adulthood: Hierarchical linear modeling analyses of two longitudinal samples. Journal of Personality and Social Psychology, 83, 752-766. https://doi.org/10.1037/0022-3514.83.3.752

Herlitz, A., Nilsson, L. G., \& Backman, L. (1997). Gender differences in episodic memory. Memory \& Cognition, 25, 801-811. https://doi. org/10.3758/Bf03211324

Lucas, J. A., Ivnik, R. J., Smith, G. E., Bohac, D. L., Tangalos, E. G., Kokmen, E., ... Petersen, R. C. (1998). Normative data for the Mattis Dementia rating scale. Journal of Clinical and Experimental Neuropsychology, 20, 536-547. https://doi.org/10.1076/ jcen.20.4.536.1469

Luchetti, M., Terracciano, A., Stephan, Y., \& Sutin, A. R. (2016). Personality and cognitive decline in older adults: Data from a longitudinal sample and meta-analysis. Journals of Gerontology. Series B, Psychological Sciences and Social Sciences, 71, 591-601. https:// doi.org/10.1093/geronb/gbu184

Maldonato, N. M., Sperandeo, R., Dell'Orco, S., Cozzolino, P., Fusco, M. L., Iorio, V. S., ... Cipresso, P. (2017). The relationship between personality and neurocognition among the american elderly: An epidemiologic study. Clinical Practice \& Epidemiology in Mental Health, 13, 233-245. https://doi.org/10.2174/174501790171301 0233

Marsh, H. W., Nagengast, B., \& Morin, A. J. S. (2013). Measurement invariance of big-five factors over the life span: ESEM tests of gender, age, plasticity, maturity, and la dolce vita effects. Developmental Psychology, 49, 1194-1218. https://doi.org/10.1037/ a0026913

Mccrae, R. R. (1987). Creativity, divergent thinking, and Openness to Experience. Journal of Personality and Social Psychology, 52, 1258-1265. https://doi.org/10.1037/0022-3514.52.6.1258

McCrae, R. R. (2010). The Place of the FFM in Personality Psychology Psychological Inquiry, 21, 57-64. https://doi.org/10.1080/10478 401003648773.

McCrae, R. R., \& Costa, P. T. Jr (2010). NEO Inventories Professional Manual. Lutz, FL: Psychological Assessment Resources.

McCrae, R. R., \& John, O. P. (1992). An Introduction to the Five-Factor Model and Its Applications. Journal of Personality, 60(2), 175-215. https://doi.org/10.1111/j.1467-6494.1992.tb00970.x 
McCrae, R. R., Martin, T. A., \& Costa, P. T. (2005). Age trends and age norms for the NEO Personality Inventory-3 in adolescents and adults. Assessment, 12, 363-373. https://doi.org/10.1177/10731 91105279724

McCrae, R. R., Terracciano, A., \& Personality Profiles of Cultures, P. (2005). Universal features of personality traits from the observer's perspective: Data from 50 cultures. Journal of Personality and Social Psychology, 88, 547-561. https://doi. org/10.1037/0022-3514.88.3.547

Moutafi, J., Furnham, A., \& Crump, J. (2003). Demographic and personality predictors of intelligence: A study using the Neo personality inventory and the Myers-Briggs type indicator. European Journal of Personality, 17, 79-94. https://doi.org/10.1002/per.471

Moutafi, J., Furnham, A., \& Paitiel, L. (2004). Why is Conscientiousness negatively correlated with intelligence? Personality and Individual Differences, 37, 1013-1022. https://doi.org/10.1016/j. paid.2003.11.010

Moutafi, J., Furnham, A., \& Paltiel, L. (2005). Can personality factors predict intelligence? Personality and Individual Differences, 38, 1021-1033. https://doi.org/10.1016/j.paid.2004.06.023

Nooner, K. B., Colcombe, S. J., Tobe, R. H., Mennes, M., Benedict, M. M., Moreno, A. L., ... Milham, M. P. (2012). The NKI-Rockland sample: a model for accelerating the pace of discovery science in psychiatry. Frontiers in Neuroscience, 6, 152.

Raine, A., Reynolds, C., Venables, P. H., \& Mednick, S. A. (2002). Stimulation seeking and intelligence: a prospective longitudinal study. Journal of Personality and Social Psychology, 82, 663-674. https://doi.org/10.1037/0022-3514.82.4.663

Rammstedt, B., Danner, D., \& Martin, S. (2016). The association between personality and cognitive ability: Going beyond simple effects. Journal of Research in Personality, 62, 39-44. https://doi. org/10.1016/j.jrp.2016.03.005

Reeve, C. L., Meyer, R. D., \& Bonaccio, S. (2006). Intelligencepersonality associations reconsidered: The importance of distinguishing between general and narrow dimensions of intelligence. Intelligence, 34, 387-402. https://doi.org/10.1016/j. intell.2005.11.001

Reitan, R. M. (1978). Manual for administration of neuropsychological test batteries for adults and children. Sant Antonio, TX: Psychological Corporation.

Revelle, W. (2019). psych: Procedures for Psychological, Psychometric, and Personality Research. Northwestern University, Evanston, Illinois. R package version 1.9.12, https://CRAN.R-project.org/ package $=$ psych

Roberts, B. W., \& DelVecchio, W. F. (2000). The rank-order consistency of personality traits from childhood to old age: A quantitative review of longitudinal studies. Psychological Bulletin, 126, 3-25. https:// doi.org/10.1037/0033-2909.126.1.3

Roberts, B. W., \& Mroczek, D. K. (2008). Personality trait change in adulthood. Current Directions in Psychological Science, 17, 31-35. https://doi.org/10.1111/j.1467-8721.2008.00543.x

Roberts, B. W., Walton, K. E., \& Viechtbauer, W. (2006). Patterns of mean-level change in personality traits across the life course: A meta-analysis of longitudinal studies. Psychological Bulletin, 132, 1-25. https://doi.org/10.1037/0033-2909.132.1.1

Robinson, M. D., \& Tamir, M. (2005). Neuroticism as mental noise: A relation between Neuroticism and reaction time standard deviations. Journal of Personality and Social Psychology, 89, 107-114. https:// doi.org/10.1037/0022-3514.89.1.107
Robison, M. K., Gath, K. I., \& Unsworth, N. (2017). The neurotic wandering mind: An individual differences investigation of Neuroticism, mind-wandering, and executive control. Quarterly Journal of Experimental Psychology, 70, 649-663. https://doi. org/10.1080/17470218.2016.1145706

Rosseel, Y. (2012). lavaan: An R package for structural equation modeling. Journal of Statistical Software, 48(2), 1-36.

Salthouse, T. A. (2004). Localizing age-related individual differences in a hierarchical structure. Intelligence, 32, 541-561. https://doi. org/10.1016/j.intell.2004.07.003

Salthouse, T. A. (2009). Decomposing age correlations on neuropsychological and cognitive variables. Journal of the International Neuropsychological Society, 15, 650-661. https://doi.org/10.1017/ S1355617709990385

Salthouse, T. A., \& Ferrer-Caja, E. (2003). What needs to be explained to account for age-related effects on multiple cognitive variables? Psychology and Aging, 18, 91-110. https://doi.org/10.1037/0882-7974.18.1.91

Salthouse, T. A., Habeck, C., Razlighi, Q., Barulli, D., Gazes, Y., \& Stern, Y. (2015). Breadth and age-dependency of relations between cortical thickness and cognition. Neurobiology of Aging, 36, 30203028. https://doi.org/10.1016/j.neurobiolaging.2015.08.011

Saylik, R., Szameitat, A. J., \& Cheeta, S. (2018). Neuroticism related differences in working memory tasks. PLOS ONE, 13(12), e0208248. https://doi.org/10.1371/journal.pone.0208248

Schafer, J. L., \& Graham, J. W. (2002). Missing data: Our view of the state of the art. Psychological Methods, 7, 147-177. https://doi. org/10.1037/1082-989X.7.2.147

Schaie, K. W., Willis, S. L., \& Caskie, G. I. L. (2004). The Seattle longitudinal study: Relationship between personality and cognition. Aging Neuropsychology and Cognition, 11, 304-324. https://doi. org/10.1080/13825580490511134

Schmidt, M. (1996). Rey auditory verbal learning test: A handbook. Los Angeles, CA: Western Psychological Services.

Schmitt, D. P., Realo, A., Voracek, M., \& Allik, J. (2008). Why can't a man be more like a woman? Sex differences in Big Five personality traits across 55 cultures. Journal of Personality and Social Psychology, 94, 168-182. https://doi.org/10.1037/0022-3514.94.1.168

Segel-Karpas, D., \& Lachman, M. E. (2016). Social contact and cognitive functioning: The role of personality. The Journals of Gerontology Series B: Psychological Sciences and Social Sciences, 00, 1-11. https://doi.org/10.1093/geronb/gbw079

Sharp, E. S., Reynolds, C. A., Pedersen, N. L., \& Gatz, M. (2010). Cognitive engagement and cognitive aging: Is Openness protective? Psychology and Aging, 25, 60-73. https://doi.org/10.1037/a0018748

Smith, T. W., \& Spiro, A. (2002). Personality, health, and aging: Prolegomenon for the next generation (vol 36, pg 363, 2002). Journal of Research in Personality, 36, 661-661. https://doi. org/10.1016/S0092-6566(02)00518-4

Soubelet, A. (2011). Age-cognition relations and the personality trait of Conscientiousness. Journal of Research in Personality, 45, 529534. https://doi.org/10.1016/j.jrp.2011.06.007

Soubelet, A., \& Salthouse, T. A. (2011). Personality-cognition relations across adulthood. Developmental Psychology, 47, 303-310. https:// doi.org/10.1037/a0021816

Specht, J., Egloff, B., \& Schmukle, S. C. (2011). Stability and Change of Personality Across the Life Course: The Impact of Age and Major Life Events on Mean-Level and Rank-Order Stability of the Big Five. Journal of Personality and Social Psychology, 101(4), 862882. https://doi.org/10.1037/a0024950 
Srivastava, S., John, O. P., Gosling, S. D., \& Potter, J. (2003). Development of personality in early and middle adulthood: Set like plaster or persistent change? Journal of Personality and Social Psychology, 84, 1041-1053. https://doi.org/10.1037/0022-3514.84.5.1041

Stern, Y. (2009). Cognitive reserve. Neuropsychologia, 47, 2015-2028. https://doi.org/10.1016/j.neuropsychologia.2009.03.004

Stern, Y., Habeck, C., Steffener, J., Barulli, D., Gazes, Y., Razlighi, Q., ... Salthouse, T. (2014). The reference ability neural network study: Motivation, design, and initial feasibility analyses. NeuroImage, 103, 139-151. https://doi.org/10.1016/j.neuroimage.2014.09.029

Stock, A. K., \& Beste, C. (2015). Conscientiousness increases efficiency of multicomponent behavior. Scientific Reports, 5, 15731. https://doi.org/10.1038/srep15731

Sutin, A. R., Stephan, Y., \& Terracciano, A. (2018). Facets of Conscientiousness and objective markers of health status. Psychology and Health, 33, 1100-1115. https://doi.org/10.1080/08870 446.2018.1464165

Terracciano, A., \& Sutin, A. R. (2019). Personality and Alzheimer's disease: An integrative review. Personality disorders, 10(1), 4-12. https://doi.org/10.1037/per0000268

Terracciano, A., McCrae, R. R., Brant, L. J., \& Costa, P. T., Jr. (2005). Hierarchical linear modeling analyses of the NEO-PI-R scales in the Baltimore Longitudinal Study of Aging. Psychology and Aging, 20, 493-506. https://doi.org/10.1037/0882-7974.20.3.493

Terry, D. P., Puente, A. N., Brown, C. L., Faraco, C. C., \& Miller, L. S. (2013). Openness to Experience is related to better memory ability in older adults with questionable dementia. Journal of Clinical and Experimental Neuropsychology, 35, 509-517. https://doi. org/10.1080/13803395.2013.795932

Voyer, D., Voyer, S., \& Bryden, M. P. (1995). Magnitude of sex-differences in spatial abilities-A metaanalysis and consideration of critical variables. Psychological Bulletin, 117, 250-270. https://doi. org/10.1037/0033-2909.117.2.250

Waggel, S. E., Lipnicki, D. M., Delbaere, K., Kochan, N. A., Draper, B., Andrews, G., ... Brodaty, H. (2015). Neuroticism scores increase with late-life cognitive decline. International Journal of Geriatric Psychiatry, 30, 985-993. https://doi.org/10.1002/gps.4251

Wechsler, D. (1997). Wechsler adult intelligence scale (3rd ed., pp. 684-690). Sant Anotni, TX: Harcourt Assessment.

Wechsler, D. (2001). The Wechsler test of adult reading (WTAR). San Antonio, TX: Psychological Corporation.

Weisberg, Y. J., DeYoung, C. G., \& Hirsh, J. B. (2011). Gender differences in personality across the ten aspects of the Big Five. Frontiers in Psychology, 2, 178. https://doi.org/10.3389/fpsyg.2011.00178
Weiss, A., Costa, P. T., Karuza, J., Duberstein, P. R., Friedman, B., \& McCrae, R. R. (2005). Cross-sectional age differences in personality among medicare patients aged 65 to 100. Psychology and Aging, 20, 182-185. https://doi.org/10.1037/0882-7974.20. 1.182

Wechsler, D. (2005). Wechsler Individual Achievement Test 2nd Edition (WIAT II). London: The Psychological Corp.

Wechsler, D. (2011). Wechsler Abbreviated Scale of Intelligence, 2nd ed. San Antonio, TX: Psychological Corporation.

Wettstein, M., Tauber, B., Kuzma, E., \& Wahl, H. W. (2017). The interplay between personality and cognitive ability across 12 years in middle and late adulthood: Evidence for reciprocal associations. Psychology and Aging, 32, 259-277. https://doi.org/10.1037/pag00 00166

Wolf, M. B., \& Ackerman, P. L. (2005). Extraversion and intelligence: A meta-analytic investigation. Personality and Individual Differences, 39, 531-542. https://doi.org/10.1016/j.paid.2005.02.020

Wrzus, C., \& Roberts, B. W. (2017). Processes of Personality Development in Adulthood: The TESSERA Framework. Personality and Social Psychology Review, 21(3), 253-277. https://doi. org/10.1177/1088868316652279

Ziegler, M., Cengia, A., Mussel, P., \& Gerstorf, D. (2015). The Openness-fluid-crystallized-intelligence (OFCI) model applied to late adulthood. Psychology and Aging, 30, 573-588. https://doi. org/10.1037/a0039493

Ziegler, M., Danay, E., Heene, M., Asendorpf, J., \& Bühner, M. (2012). Openness, fluid intelligence, and crystallized intelligence: Toward an integrative model. Journal of Research in Personality, 46, 173-183. https://doi.org/10.1016/j.jrp.2012.01.002

\section{SUPPORTING INFORMATION}

Additional supporting information may be found online in the Supporting Information section.

How to cite this article: Simon SS, Lee S, Stern Y. Personality-cognition associations across the adult life span and potential moderators: Results from two cohorts. Journal of Personality. 2020;88:1025-1039. https://doi.org/10.1111/jopy.12548 